\title{
Amistades literarias: Hugo Wast
}

\begin{abstract}
A SPIRamos a promover y desarrollar una "amistad literaria" dando algunas noticias acerca del destacado escritor argentino a quien se conoce por su seudónimo: "Hugo Wast." Este autor no necesita presentación, claro está, para la mayoría de los lectores de esta revista. Sin embargo, se desea of recer a todos algunos "informes" sobre la vida íntima del escritor valiéndonos de ciertas obras suyas en las que hace referencia a las luchas que ha sostenido hasta llegar a la posición que actualmente ocupa en el mundo de las letras. Creo que quienes ya conocen a Hugo Wast me seguirán con interés renovado, y los demás establecerán así relaciones con él. Es muy posible que más tarde aparezcan otros artículos dedicados a iniciar una serie de "amistades literarias".
\end{abstract}

Hugo Wast, como escritor, ha agradado a millares de lectores, para quienes sigue siendo el novelista preferido. ${ }^{1}$ Tristán Valdaspe, historiador de la literatura argentina, lo considera como "el novelista más popular y fecundo de nuestro país". ${ }^{2}$ Arturo TorresRioseco lo llama "el novelista moderno más leído en español", habiéndolo comparado con Jules Verne, por cultivar la novela de aventuras. Dice que el autor trabaja con entusiasmo y embellece sus frases con solicitud. Se cita esto para condenar aquel sabotaje intelectual de un pequeño grupo de críticos que sin leer al autor lo juzgan liviano, sólo por el gran número de libros que ha producido.

Conviene decir, en cuanto al conocimiento de Hugo Wast, que en un sentido figurado nos lo presentaron hace varios años, y la manera de efectuarse la presentación no carece de interés. El que 
lo presentó en aquella época, ya algo remota, era un tal Peter Goldsmith, creador de un plan original y sugerente, cuyo fin era un intercambio en las dos Américas, y que era como sigue:

Fundó la revista Inter-A merica, y escrito así el título, se leía tanto en inglés como en espariol. De esta manera dió uno de los primeros pasos en el movimiento que hoy conocemos bajo el nombre de la Política del Buen Vecino. La revista apareció en el mes de octubre de 1917. Desgraciadamente, no duró más allá de 1926, cuando de repente y sin sucesor murió el fundador y redactor de ella. ${ }^{3}$

Los números de esta revista aparecían alternativamente en inglés y en español. Los de lengua inglesa contenían, traducidos del español, los mejores artículos, cuentos y selecciones literarias que que el redactor hallaba en los periódicos de la América Hispana, o de otra manera: presentados por los autores hispanoamericanos. En los meses en que correspondía hacer la publicación en español, aparecían traducciones de obras norteamericanas, ofreciendo así una variedad agradable y de muchísimo valor para ambos mundos del hemisferio occidental. Como hoy en día no existe continuador de tan buena obra, nos preguntamos en vano: ¿Quién se ocupará de tarea tan importante?

Se ha dicho que al autor a quien vamos a estudiar se le conoce por su seudónimo, y sin duda habrá quien se haya preguntado de dónde sacaría el autor tal "nombre de pluma". Cualquier enigma es un estímulo, un estímulo para el intelecto, tanto como para la imaginación, y no lo es menos en este caso. Algunos dirán que el de Hugo Wast es demasiado sencillo, para merecer un estudio profundo, ya que no es más que un anagrama formado con el nombre de pila: "Gustavo." En esto hay razón, y es que de Gustavo sale Ugovast, y dividiendo el nombre español en dos partes resulta Ugo Vast (Hugo Wast).

En la parte que el autor llama prólogo, de la primera edición de su Flor de durazno, nos cuenta cómo un extranjero, un tal Hugo Wast, dejó un manuscrito en manos del autor, para que éste cuidara de publicarlo después de la muerte del forastero, viejo y enfermo. De allí nace la idea del pseudónimo escogido por el señor doctor Gustavo Martínez Zuviría; solución mucho más amena que el mero uso del anagrama. En ese prólogo de su Flor de durazno, hace hablar a un viejo, el extranjero, como sigue: 
Es el mes de abril, y tengo el presentimiento de que antes de que se pase el invierno, haré mi último paseo por este camino abandonado. Es la hora y no me quejo... Deseaba vivir hasta que hubiera acabado mi libro. Está terminado ya... Refiero una historia verdadera, algunos de los protagonistas viviendo todavía. En el camino hacia el cementerio he visto pasar uno de ellos hoy... Una rubia le sirve de lazarillo, pues es ciego. Casi todos los dias hace este viaje, y a veces nuestros pasos se han cruzado.

Cuando supe su historia, me vino la idea de este libro. He deseado la vida sólo para concluirlo, por llevarme del mundo cuando me presente al tribunal de Dios, entre mis inumerables dias estériles, unas pocas horas fecundas, que depondrán en mi favor. Lo he escrito como quien hace un testamento... ¿Habrá quién se hiera con él? No sé, ni lo sabré. Se publicará cuando yo duerma ya en el tranquilo cementerio que visito en los días de sol. Y si las almas de los muertos se mezclan en las cosas de la vida, mi alma se alegrará, cuando en el corazón de uno solo de los que me lean, brote esa flor de simpatía hacia los dolores ignorados de las gentes humildes.

Abril 30 de 1910.

H. W.

El viejo de marras, el extranjero, quedó asi presentado en el prólogo de la primera edición de Flor de durazno, y un mes después

... en el cementerio de un pueblito de las sierras de Córdoba se plantaba una cruz más, señalando el sitio en que hoy descansa de sus fatigas el autor de este libro. Una señora en cuya casa se hospedaba y murió nos ha enviado el manuscrito, comunicándonos en su carta que ésa fué la última voluntad del muerto. 4

Creado así en su imaginación tanto el manuscrito como el episodio del extranjero, Gustavo Martínez Zuviría se presentó al mundo literario bajo las características de Hugo Wast, pseudónimo que ha vivido tanto como su creador.

Preguntemos ahora a este Hugo Wast sobre el éxito de la obra con la cual inició su carrera de novelista y cómo ha logrado mantener vivo el nombre del extranjero durante años, después de las últimas visitas que hacía aquel viejecito al tranquilo cementerio campestre. Estamos en marzo del año 1930, y nos encontramos con el autor 
en París, en alguna librería, digamos, donde está buscando primeras ediciones, que con mucho afán colecciona, y casi lo oímos decirse a sí mismo:

Tengo motivos para saber quién posee el primer ejemplar que se vendió de la edición original de Flor de durazno. Era en 1911. La novela acababa de aparecer, pero los libreros no la mostraban en sus escaparates, "porque no se vendía". iY es claro! No se vendía porque ellos no la mostraban.

Paseándome por la calle Florida con el doctor Nicanor de Nevares, le dije: "Hágame el favor: entre en lo de Arnoldo Moen y pida un ejemplar de Flor de durazno. Sé que todavía no han deshecho el paquete. Será el primero que se venda y me traerá suerte que usted sea su comprador."

Cinco minutos después, el doctor Nevares tenía su ejemplat de aquella primera edición ... Si no la ha perdido, seguramente dentro de cien años podrá venderla a un bibliófilo por el doble de lo que le costó. 5

Queda pensativo el autor, probablemente reflexionando en el pasado, $y$ cuando rompe el silencio es para decir:

Aquella primera edición contenia ... bastantes gazapos. Sucedia (en la novela) que el día que se casó la madre de Rina, la comitiva de campesinos fué y volvió a caballo de la iglesia. La recién casada perdió su rebenque, y alguien, para que no se quedata atrás, le alcanzó una ramita de durazno.

En aquellos tiempos (y ahora todavía) mis conocimientos de arboricultura eran asaz mediocres. Yo creia que los duraznos se multiplicaban de gajos... Por esa tazón mi protagonista. al llegar a casa, plantó en medio del patio su improvisado rebenque, y esa ramita prendió y con los años se transformó en árbol cuyas flores habian de ser el talismán del corazón humilde y romántico de Rina. ${ }^{6}$

Don Jorge Mitre me reveló confidencialmente que los duraznos no crecen de gajos. :Dios se lo pague! [Pero en qué aprieto me puso! Aquel episodio estaba injertado en el simbolismo de la obra, y tuve que desprenderto no sé cómo. 'Cuán cierto es como dice Kempis, que quién añade ciencia, añade dolor! 7

El lector reconocerá en esto un espíritu juguetón, porque hay a nuestro alcance ciertos datos sobre los estudios del autor: que siguió con éxito los cursos de Derecho en la Universidad, y que después de recibir el doctorado en Derecho en 1907, fué nombrado 
profesor de Economía Política en su alma mater, la Universidad de Litoral. Ha sido dos veces condecorado por la Real Academia Española, además de que ganó el gran premio literario ofrecido por el gobierno argentino. Aparte de los honores citados, si no para coronarlos, es desde hace muchos años director de la Biblioteca Nacional, en Buenos Aires.

Habrá sin duda entre nuestros "amigos lectores" algunos que estarán esperando ver aparecer una lista de las obras del autor. Para complacer a esas personas, hela aquí:

Ruth, Magdalena, Gustavo, Graciela, María Elena, Matilde, Bety, Teresa, Jorge, Myriam y Marcelo.

Alguien dirá: "Pues son títulos muy difíciles de interpretar, en cuanto a su posible contenido." Tendrá razón tal lector, pero los que conocen al autor sabrán que estos son títulos de otra índole: son las "obras vivientes" del autor, los hijos del matrimonio Martínez Zuviría, y han sido muchas veces quienes le inspiraron sus novelas.

Existe en Hugo Wast un interés por su familia que da gusto encontrar en la vida de cualquiera, y todavía más en uno de nuestros escritores predilectos. Cuando él menciona a alguno de sus deudos, to hace con no disimulado afecto. Por ejemplo, cuando nos presenta a su abuela, es para hablar de la manera como ella veía las cosas, en contraste con el punto de vista del joven autor. Se trataba de la aparición de éste en el mundo literario, antes de que él concibiera el pseudónimo que había de marcar su éxito venidero como escritor. La novela tenía por título i Loca...! Respecto a la intervención de su abuela dice el autor:

Necesitaba dejar un solo hijo a una viuda que tenía seis. Había oído contar que en una espantosa epidemia que azotó mi ciudad natal, la difteria le llevó en ocho días sus ocho hijitos a una madre, y me pareció que disminuyendo un poco la velocidad del flagelo y el número de los pequeños cadáveres, podría valerme de aquel recurso. Maté, o mejor dicho, hice matar por la difteria en quince días los cinco chicos que me estorbaban.

Mi abuela... tenía muy buen sentido artístico, y en lugar de enternecerse cuando leyó mi cuento, se puso a reír, lo cual ofendió mi vanidad, y me desconcertó.

- Qué matanza de inocentes, hijito! INi el rey Herodes!

- ¿Pero cómo es eso, mamita? ¿No me ha contado usted de una tía a quien la difteria le llevó ocho hijos en una semana? 

un cuento.

- Sí, desgraciadamente; pero aquello fué verdad y esto es

Ella no se explicó más largo, porque no sabía analizar sus razones estéticas, y solamente años después he comprendido la gran lección de literatura que me dió la santa viejita: no siempre lo verdadero es verosímil, $\mathrm{y}$ en arte solamente lo verosímil es verdadero. 8

Se nos ocurre preguntar al escritor cómo le ha ido con sus obras escritas y si el éxito ha premiado a sus esfuerzos. No asiente sobre lo del éxito, mas está dispuesto a reírse y contar bromas respecto a su falta de éxito financiero, en sus primeros días. Hubo épocas de verdadera necesidad:

A la madrugada las inefables campanas me quitaron el sueño y púseme a reconocerlas en la singular sinfonía. Esas de voz nerviosa y delgadita son de las monjas Teresas; esas robustas y zumbadoras son las de la Compañía...

- Esa otra del lechero que pasa con sus vacas! me gritó mi estómago, vacío desde las doce del día anterior...

Mi pensamiento voló a don Olimpio Linares. Iba -oh sueño dorado que me quitaba el otro sueño- a vivir de la literatura. Llegué a la Plaza San Martín cuando la librería de Linares estaba cerrada aún. Y empecé a dar vueltas, admirando cosas que me sabia de memoria... iPero he aquí que aparece mi hombre!

-iDon Olimpio!

- ¿Usted por aquí? iTanto gusto! ¡Pase! Siéntese, mientras yo recojo estas cartas que me han echado por el buzón.

Ayudé al buen señor a recoger su correspondencia y antes que llegaran sus empleados me animé a preguntar:

- ¿Cómo anda eso?

- ¿La salud? ¡Bien!

-Me alegro ... ¿Y nuestro asuntito?

- Los negocios van mal; hay crisis, este gobierno...

Me respondía abriendo cartas... y sin comprender gota de lo que yo quería decirle.

-Siento mucho que no vayan bien los negocios ... pero se refiere a mis libros.

- ¿Sus libros? ¿Hombre, discúlpeme! . . Me parece que se han vendido muchos.

- ¿Se habrán vendido todos los ejemplares?

- Todos, tal vez no, pero muchos, muchos... Ahora cuando venga el empleado vamos a preguntarle... 
No tardó en llegar el empleado, cuando ya el librero había concluido sus cartas.

- ¿Te acordás, che, cuántos ejemplares se han vendido del Espititismo, digo del Naturalismo? Este joven es el autor.

- ¿Ah, sí? iMucho gusto de conocerlo!

-i Igualmente! dije yo, estrechando la mano que me tendía. nillas.

-Este joven es además sobrino del canónigo López $\mathrm{Ca}$ -

- - Justamente! exclamó el empleado. -El señor canónigo compró un ejemplar del Natutalismo y otro ejemplar de Los dos grumetes... vendido?

—iBueno! De ésos ya sabía... ¿Cuántos más se habrán

-iMuchos, muchos! exclamó don Olimpio, entregándose

a sus tareas habituales y dejando $\mathrm{mi}$ asunto al empleado. 9

Nuestro lector habrá sospechado el final de este pequeño drama. Los "muchos, muchos" ejemplares mencionados por don Olimpio se redujeron a los dos ejemplares comprados por el buen tío caritativo del autor, y el pequeño error por parte de don Olimpio no lo era del todo, porque una obra titulada El espiritismo al alcance de todos estaba realmente gozando de gran popularidad en el momento, y era este título el que venía a la mente del buen viejito, siempre que trataba de acordarse de la venta de un ejemplar deI Naturalismo de nuestro autor.

No era divertida la situación, pero el joven Martínez Zuviría trató de reírse, y con tanto éxito que tuvieron que acompañarlo don Olimpio y el empleado. El autor dice que no se quejaba de la risa del empleado, quien era un tanto flacucho; pero la de don Olimpio, que era corpulento y de buen humor, lo lastimaba mucho. Sin embargo, no quería ser menos que ellos y se reía por ambos.

Echamos cuentas: ochenta centavos por el Naturalismo, cuarenta por Los dos grumetes, hacían un peso y veinte. Quitada la comisión del 25 por ciento que yo asignaba al librero, quedaban noventa centavos a mi favor, que don Olimpio me entregó en el acto. Ese era el dinero con que iba a costear mis vacaciones. ${ }^{10}$

Sigue el autor con la relación de su malestar y de su breve odisea en busca de consuelo:

Tenía ojos y no veía; oídos y no oía; estómago vacío y no lo sentía... Parece que el único sentido que me quedaba era 
el olfato, pues al doblar una esquina sentí olor a pan caliente... Entré al boliche y gasté mis noventa centavos en pan caliente, $y$ me fui a devorar mi humillación en la solitaria casa de mi abuela. Pero como cada bocado de humillación pasaba en compañía de aquel manjar de principes, resultóme tolerable su amargura... Y de allí partí a visitar a mi tío el canónigo. ${ }^{11}$

Para desconcertar todavía más al miserable joven autor, resultó que su tío se había ido a pasar lejos de casa las vacaciones del verano. Ese mismo día escribió Martínez Zuviría a su padre, confiándole sin reservas sus pesares como escritor en embrión y pidiéndole el dinero necesario para continuar su viaje. Lo verdaderamente malo de su situación se aclara en esta pequeña confesión:

No tenía ya ni para la estampilla de la carta, que eché sin ese condimento al buzón. ${ }^{12}$.

Lentamente pasaron los dias, y la ciudad quemada por el implacable sol de un fuerte verano vino a ser un lugar desierto. Las visitas matinales a la librería de don Olimpio, como las de la tarde, eran inútiles. Por juego, mal juzgado por el autor, díjole don Olimpio una mañana:

-Ayer vendí cuatro, pero no del suyo, sino del otro, $E l$ espiritismo al alcance de todos. 13

Sin ánimo para seguir y creyendo que a lo mejor se le iría el alma, el autor se mantenía vivo únicamente por las buenas agencias de una anciana tía. Llegó un día la criada de ésta, trayendo una canasta de proporciones generosas. Iba bien cerrada, y para mejor asegurar que nadie, excepto el legítimo dueño, conociese su contenido, había tomado la tía la precaución de coser la tapa. Dijo la portadora :

Su tía, que ayer lo encontró en la calle, vino anoche a visitarlo, trayéndole estas empanaditas. Dice que siente mucho no verlo; que hoy se va al campo, y que le ha gustado lo indecible ese librito que usted ha compuesto. 14

Durante días que parecieron al autor muy largos comió las empanaditas, sin dejar de notar su delicioso sabor, pero al mismo tiempo deseando que hubiera un poco más de variedad en sus ali- 
mentos. Haciendo luego reminiscencias sobre aquella semana y la inolvidable experiencia de las empanaditas, nos relata lo que sigue:

¿Deliciosas empanaditas aquéllas! Mi tía era una artista maravillosa. Las construía de una masa tierna y exquisita; les rellenaba el buchecito con una cucharada de dulces diferentes, de membrillo, de durazno, de batata; las metia en el horno hasta que se doraban, poniéndose quebradizas como un barquillo, y entonces las pintaba con azúcar desleído en clara de huevo... ¿Qué pasión tenía yo por las empanaditas! Pero cuando hube pasado cinco días engullendo tres como desayuno, seis como almuerzo, doce como cena, les tomé un odio feroz.

Así viví cuatro, cinco, seis días. Al séptimo descansé. 15 Había dado fin al contenido de la canasta. Me dispuse a bien morir. Pero al anochecer el cartero echó por el buzón la carta esperada. Mi amado padre no había aún recibido la mía, que andaría persiguiéndolo por diversas direcciones, pero la voz de la sangre le advirtió que su hijo estaba a punto de perecer de inanición, después de haber agotado sus derechos de autor. $Y$ me mandaba un giro. Lé la carta y la cifra a la luz de la Vía Láctea. La vela se me había consumido. ¿Pero qué me importaba! ¡Qué desquite para el día siguiente!

Tuve esa noche los sueños más groseros: nada dulce, todo craso y áspero, pan con grasa, chorizos fritos y ensalada de cebolla, y para postre jamón del diablo. Comencé en don Quijote, y acabé en Sancho Panza. 16

* $\quad * \quad *$

Terminamos aquí la presentación de Hugo Wast deseando que no se haya semejado a la manera formal de presentar a un forastero que nos es totalmente desconocido, sino que haya logrado más bien el propósito de revivir algunas reminiscencias, sobre ciertas fases de la vida de un viejo amigo. Lo que queda expresado podrá tal vez despertar en muchos lectores el recuerdo de una larga serie de acontecimientos relacionados con la vida del autor. $\mathrm{Y}$ si para algunos éste era hasta ahora desconocido en cuanto a los detalles que de él se han dado, nos habrán de agradecer, seguramente, el haber tratado el tema en estas páginas; sobre todo, después de saborear las obras de Hugo Wast. Casi no habrá quien no se sienta satisfecho, tras su lectura, donde hallará según los preceptos de Horacio, lo 
útil mezclado con lo agradable, y el lector no dará por perdido su tiempo, ya que se considerará enriquecido por esta nueva "amistad literaria" que hoy nace o que se robustece, si ya existía.

\section{Robert Stanley Whitehouse University of Miami, Fla.}

\section{$\mathrm{NOTAS}$}

1 José María Samperio. Artículo traducido al inglés con el título: An author whose works have appealed to thousands, en INTER-AMERICA, Vol. VIII, N2 6, August, 1925.

-2 Tristán Valdaspe: Historia de la literatura argentina e hispanoamericana, p. 221.

3 No se confunda INTER-AMERICA con Inter-American, revista también de vida corta, porque apenas llegó a terminar el quinto año, cuando cesó de existir.

4 Flor de durazno, 7.

5 Naves - Oro - Sueños, 245, 246.

6 La heroína de Flot de dutazno.

7 Naves - Oto - Sueños, 246, 247.

8 Confidencias de un novelista, 35, 36, 37.

9 Confidencias de un novelista, $255-260$.

10 Confidencias de un novelista, 263, 264.

11 Ibid., $264 \& 266$.

12 Confidencias de un novelista, 270.

13 Ibid., 277.

14 Ibid., 276.

15 Referencia a la Santa Biblia, frecuente en Hugo Wast. Véase Génesis $2: 2$.

16 Confidencias de un novelista, 278, 279 \& 280. 